Article Type: Research Paper

\title{
Analisis Faktor-faktor yang Mempengaruhi Tingkat Kunjungan Wisata di Objek Wisata Alam Kalibiru Kulon Progo, Yogyakarta
}

\author{
Rizki Lestari ${ }^{1}$, dan Dyah Setyawati Dewanti ${ }^{1}$
}

\begin{abstract}
Abstrak: Penelitian ini bertujuan untuk mengetahui faktor-faktor yang mempengaruhi kunjungan wisatawan di Wisata Alam Kalibiru. Pengambilan sampel dalm penelitian ini dilakukan dengan menggunakan metode accidental sampling di mana teknik pengambilan sampel dilakukan secara kebetulan dari pengunjung obyek wisata alam Kalibiru. Model analisis yang digunakan dalam penelitian ini adalah regresi linear berganda dengan tingkat kunjungan sebagai variabel dependen, sementara terdapat lima variabel sebagai variabel independen, yaitu usia, pendidikan, pendapatan, jarak, dan biaya perjalanan. Hasil penelitian ini menunjukkan bahwa dari kelima variabel independen dalam persamaan regresi, terdapat dua variabel yang berpengaruh signifikan terhadap tingkat kunjungan yaitu jarak dan pendapatan. Sedangkan variabel usia, pendidikan, dan biaya perjalanan tidak berpengaruh signifikan terhadap tingkat kunjungan wisatawan.
\end{abstract}

AFILIASI:

${ }^{1}$ Department of Economics, Faculty of Economics and Business, Universitas Muhammadiyah Yogyakarta, Yogyakarta, Indonesia.

*KORESPONDENSI:

rizki.lestari.2015@fe.umy.ac.id

ARTIKEL INI TERSEDIA DI:

http://journal.umy.ac.id/index.php/jerss

DOI: $10.18196 /$ jerss.030214

Kata Kunci: Tingkat kunjungan; pendapatan; jarak; usia; pendidikan; biaya perjalanan.

SITASI:

Lestari, R., \& Dewanti, D. S. (2020).

Analisis Faktor-faktor yang

Mempengaruhi Tingkat Kunjungan

Wisata di Objek Wisata Alam Kalibiru Kulon Progo, Yogyakarta. Journal of Economics Research and Social Sciences, 4(1), 134-139.

\section{Pendahuluan}

Pariwisata adalah suatu kegiatan atau aktivitas perjalanan yang dilakukan oleh seseorang untuk sementara waktu dari tempat tinggal semula ke daerah tujuan dengan alasan bukan untuk menetap atau mencari nafkah melainkan hanya untuk memenuhi rasa ingin tahu, menghabiskan waktu luang atau libur serta tujuan-tujuan lainnya (UNESCO, 2009). Dalam prespektif Islam, pariwisata disebut sebagai rihlah yang artinya aktivitas perjalanan dari suatu tempat ke tempat lain dengan tujuan tertentu. Dalam Al-Qur'an Surat al-Mulk ayat 15 Allah SWT juga berfirman "Dialah yang menjadikan bumi itu mudah bagi kamu, maka berjalanlah di segala penjurunya dan makanlah sebahagian dari rezeki-Nya. Dan hanya kepadaNya-lah kamu (kembali setelah) dibangkitkan".

Berbicara mengenai pariwisata, keindahan alam Indonesia memang tidakperlu diragukan lagi, terletak di antara dua samudera dan dua benua, memiliki lebih dari 17.000 pulau di sepanjang lima ribu kilometer garis pantai membuat Indonesia kaya akan keragaman alam dan budaya yang mengagumkan, menjadikan Indonesia surga wisata alam bagi wisatawan di seluruh belahan dunia. Salah Daerah wisata yang sangat terkenal yang dimiliki Indonesia adalah Daerah Istimewa Yogyakarta. Memiliki 4 kabupaten dan 1 Kota, Kabupaten Kulon Progo merupakan salah satu 
kabupaten di Yogyakarta yang memiliki 20 objek wisata (Dinas Kebudayaan Pariwisata dan Olahraga Kabupaten Kulon Progo, 2018). Salah satunya yaitu Wisata Alam Kalibiru. Objek wisata ini berdiri sejak bulan Maret tahun 2010 dari adanya inisiatif dan partisipasi dari masyarakat lokal yang ingin bangkit dari kemiskinan. Namun jumlah pengunjung Wisata Alam Kalibiru mengalami fluktuasi setiap tahunnya. Adapun faktorfaktor yang diduga mampu mempengaruhi minat kunjungan wisatawan untuk pergi berwisata ke Wisata Alam Kalibiru antara lain usia, tingkat pendidikan, pendapatan, jarak tempuh, dan biaya perjalanan.

\section{Tinjauan Pustaka}

Lakuhati (2018) menyimpulkan bahwa tingkat usia wisatawan mempengaruhi keputusan wisatawan untuk melakukan perjalanan wisata. Lakuhati (2018) mengatakan bahwa semakin bertambah usia seseorang maka akan semakin bertambah jumlah kunjungan wisatawan pada suatu objek wisata. Dalam penelitian Akhrom (2014), pendapatan berpengaruh terhadap keputusan wisatawan dalam melakukan perjalanan ke objek wisata. Sesuai dengan kurva permintaan, semakin besar pendapatan seseorang maka semakin besar juga konsumsi orang tersebut terhadap barang atau jasa. Selain pendapatan, biaya perjalanan juga sangat mempengaruhi keputusan wisatawan untuk melakukan sebuah perjalanan wisata. Apabila semakin mahal biaya perjalanan wisata tersebut, maka kunjungan wisatawan ke objek tersebut akan relatif rendah, begitu juga sebaliknya (Hidayat, 2011).

Menurut Mclntosh, Goeldner, dan Ritchie (1995), lama perjalanan yang ditempuh oleh wisatawan merupakan salah satu faktor yang berpengaruh terhadap arus wisatawan pada suatu objek wisata. Pada umumnya, semakin dekat objek wisata tersebut akan mempengaruhi wisawatan untuk mengunjungi tempat tersebut, begitu juga sebaliknya. Dalam hal Pendidikan, Brata, Yolaminda, dan Amalius (2018) berpendapat bahwa semakin tinggi tingkat pendidikan seseorang maka akan berpengaruh terhadap tingkat pendapatan seseorang. Secara tidak langsung, dengan meningkatnya pendapatan orang tersebut maka akan berpengaruh terhadap intensitas melakukan perjalanan wisata orang tersebut, seiring dengan meningkatnya pola konsumsi orang tersebut.

\section{Metode Penelitian}

Jenis data digunakan dalam penelitian ini adalah data primer dengan teknik pengumpulan data melalui wawancara. Metode analisis yang digunakan dalam penelitian ini adalah dengan metode OLS, yaitu uji regresi linier berganda dengan menggunakan alat analisis SPSS 15 . Uji regresi linier berganda ini digunakan untuk mengetahui hubungan antara variabel usia, tingkat pendidikan, pendapatan, jarak tempuh, dan biaya perjalanan terhadap tingkat kunjungan di Wisata Alam Kalibiru.

Adapun dinyatakan fungsi sebagai berikut:

$$
\mathrm{Y}=\mathrm{f}\left(X_{1} X_{2} X_{3} X_{4} X_{5}\right)
$$


Secara sistematis model tersebut secara sistematis dapat dituliskan sebagai berikut:

$$
\operatorname{LnY}=\alpha+\beta_{1} \operatorname{Ln} X_{1}+\beta_{2} \operatorname{Ln} X_{2}+\beta_{3} \operatorname{Ln} X_{3}+\beta_{4} \operatorname{Ln} X_{4}+\beta_{5} \operatorname{Ln} X_{5}+\mathrm{e}
$$

Di mana:

Y : Tingkat kunjungan di Wisata Alam Kalibiru

$\alpha \quad$ : Konstanta

$\beta_{1} \quad$ : Koefisien regresi

$X_{1} \quad$ : Usia pengunjung (Tahun)

$X_{2} \quad$ : Tingkat pendidikan pengunjung (Tahun)

$X_{3} \quad$ : Pendapatan yang diterima oleh pengunjung setiap bulan (Rp)

$X_{4} \quad$ : Jarak tempuh dari tempat tinggal pengunjung menuju Wisata Alam Kalibiru

$X_{5} \quad$ : Biaya perjalanan ke Wisata Alam Kalibiru (tiket masuk, transportasi, parkir, dan konsumsi)

e : Residual/ error

\section{Hasil dan Pembahasan}

Dengan melakukan beberapa pengujian asumsi klasik, penulis ingin melihat apakah data yang didapatkan bisa diolah lebih lanjut sehingga data yang dihasilkan dapat dipercaya.

Tabel 1 Hasil Uji Normalitas

\begin{tabular}{lcc} 
& & LY \\
\hline \multirow{2}{*}{ Normal Parameter a,b } & Nean & 36 \\
& Std. Deviation & -.2588 \\
Most Extreme & Absolute & .53881 \\
Differences & Positive & .102 \\
& Negative & .091 \\
Kolmogorov-Smirnov Z & & -.102 \\
Asymp. Sig. (2-tailed) & & .612 \\
\hline
\end{tabular}

Sumber: Data diolah

Pada output data di atas terlihat bahwa hasil uji normalitas menunjukkan level signifikansi lebih besar dari $\alpha(\alpha=0.05)$ yaitu sebesar $0.848>0.05$ atau sebesar $84,8 \%$ yang berarti bahwa data terdistribusi secara normal.

Tabel 2 Hasil Uji Multikolinearitas

\begin{tabular}{lcc} 
& Model & \multicolumn{2}{c|}{ Collinearity Statistics } \\
& Tolerance & VIF \\
\hline L_X1 Usia & .799 & 1.251 \\
L_X2 Pendidikan Terakhir & .802 & 1.219 \\
L_X3 Pendapatan & .752 & 1.329 \\
L_X4 Jarak Tempuh & .322 & 3.109 \\
L_X5 Biaya Perjalanan & .295 & 3.386 \\
\hline
\end{tabular}

Sumber: Data diolah 
Berdasarkan tabel hasil uji multikolinearitas di atas menunjukkan bahwa X1 (variabel usia), X2 (variabel tingkat pendidikan), X3 (variabel pendapatan), X4 (variabel jarak tempuh), dan X5 (variabel biaya perjalanan) memiliki nilai Variance Inflation Factors (VIF) seluruhnya $<10$, sehingga dapat disimpulkan bahwa tidak terdapat multikolinearitas diantara variabel independen dalam model regresi.

Tabel 3 Hasil Uji Heterokedastisitas

\begin{tabular}{|c|c|c|c|c|c|c|}
\hline \multirow{2}{*}{\multicolumn{2}{|c|}{ Model }} & \multicolumn{2}{|c|}{$\begin{array}{l}\text { Unstandardized } \\
\text { Coefficients }\end{array}$} & \multirow{2}{*}{$\begin{array}{c}\text { Standardized } \\
\text { Coefficients } \\
\text { Beta }\end{array}$} & \multirow[t]{2}{*}{$t$} & \multirow[t]{2}{*}{ Sig. } \\
\hline & & B & $\begin{array}{l}\text { Std. } \\
\text { Error }\end{array}$ & & & \\
\hline \multicolumn{2}{|c|}{ (Constant) } & .164 & 1.243 & & .132 & .895 \\
\hline L_X1 & Usia & -.101 & .483 & -.023 & -.209 & .835 \\
\hline L_X2 & Pend. Terakhir & .640 & .597 & .117 & 1.072 & .286 \\
\hline L_X3 & Pendapatan & .152 & .192 & .090 & .791 & .431 \\
\hline L_X4 & Jarak Tempuh & -.245 & .219 & -.195 & -1.121 & .265 \\
\hline L_X5 & Biaya Perjalanan & -.116 & .231 & -.091 & -.503 & .616 \\
\hline
\end{tabular}

Sumber: Data diolah

Dari hasil uji heterokedastisitas pada tabel di atas dapat dilihat bahwa nilai sigiifikan semua variabel $>0,05$ (lebih dari 0,05). Hal ini menunjukan bahwa tidak terjadi heteroskidastisitas pada model regresi, sehingga regresi dapat digunakan.

Tabel 4 Hasil Uji F Anovab

\begin{tabular}{lccccc|}
\multicolumn{1}{c}{ Model } & $\begin{array}{c}\text { Sum of } \\
\text { Squares }\end{array}$ & Df & Mean Square & F & Sig. \\
\hline Regression & 1.332 & 5 & .266 & 6.830 & $.000^{\text {a }}$ \\
Residual & 3.668 & 94 & .039 & & \\
Total & 5.000 & 99 & & & \\
\hline
\end{tabular}

Sumber: Data diolah

Berdasarkan Uji F pada tabel 4 di atas diketahui bahwa nilai signifikan model regresi secara simultan sebesar 0,000 yang berarti nilai ini lebih kecil dari significance level 0,05 (5\%). Sehingga dapat disimpulkan bahwa secara simultan variabel independen berpengaruh signifikan terhadap variabel dependen.

Tabel 5 Hasil Uji Parsial (Uji t)

\begin{tabular}{llcccc}
\hline \multicolumn{1}{c}{ Model } & \multicolumn{2}{c}{$\begin{array}{c}\text { Unstandardized } \\
\text { Coefficients }\end{array}$} & $\begin{array}{c}\text { Standardized } \\
\text { Coefficients }\end{array}$ & t & Sig. \\
& B & $\begin{array}{c}\text { Std. } \\
\text { Error }\end{array}$ & Beta \\
\hline (Constant) & -.355 & .387 & & \\
L_X1 Usia & .110 & .150 & .073 & -.917 & .361 \\
L_X2 Pend. Terakhir & -.362 & .186 & -.190 & -1.947 & .054 \\
L_X3 Pendapatan & .174 & .060 & .297 & 2.919 & .004 \\
L_X4 Jarak Tempuh & -.186 & .068 & -.427 & -2.741 & .007 \\
L_X5 Biaya Perjalanan & -.004 & .072 & -.008 & -.051 & .959 \\
\hline
\end{tabular}

Sumber: Data diolah 
Dengan nilai signifikansi sebesar $0,465>0.05$, maka dapat dikatakan bahwa variabel usia tidak berpengaruh signifikan terhadap variabel tingkat kunjungan wisatawan ke Wisata Alam Kalibiru. Hal yang sama terjadi pada variabel Pendidikan, dengan nilai signifikansi sebesar 0,054>0,05 maka dapat dikatakan bahwa variabel pendidikan tidak berpengaruh signifikan terhadap variabel tingkat kunjungan wisatawan ke Wisata Alam Kalibiru. Variabel biaya perjalanan muncul dengan nilai yang tidak sesuai dengan yang diharapkan. Dengan nilai signifikansi sebesar 0.059>0.05, dapat dikatakan bahwa tidak ada hubungan antara biaya perjalanan dengan jumlah kunjungan wisatawan pada Wisata Alam Kalibiru.

Berbeda dengan variabel pendapatan, dengan nilai signifikansi sebesar $0,004<0,05$ atau dalam kata lain menunjukan bahwa variabel pendapatan berpengaruh signifikan terhadap variabel tingkat kunjungan wisatawan ke Wisata Alam Kalibiru. 1 persen kenaikan pada pendapatan wisatawan akan mempengaruhi peningkatan jumlah kedatangan wisatawan sebesar 1.7 persen. Hal yang sama terjadi pada variabel jarak tempuh, dengan tingkat signifikansi 1 persen, peningkatan jarak tempuh sebesar 1 persen akan mengurangi jumlah wisatawan yang datang ke Wisata Alam Kalibiru sebesar 1.86 persen.

Tabel 6 Uji Koefisien Determinasi $\left(R^{2}\right)$

\begin{tabular}{cccccccccc}
\hline Model & $\mathbf{R}$ & $\begin{array}{c}\mathbf{R} \\
\text { Square }\end{array}$ & $\begin{array}{c}\text { Adjusted } \\
\text { R Square }\end{array}$ & $\begin{array}{c}\text { Std. } \\
\text { Error of } \\
\text { the } \\
\text { Estimate }\end{array}$ & $\begin{array}{c}\text { R Square } \\
\text { Change }\end{array}$ & F Change df1 & df2 & $\begin{array}{c}\text { Sig. F } \\
\text { Change }\end{array}$ \\
\hline 1 & $.516^{a}$ & .266 & .227 & .19753 & .266 & 6.830 & 5 & 94 & .000 \\
\hline
\end{tabular}

Sumber: olah data SPSS 15

Koefisien determinasi $\left(R^{2}\right)$ yang terlihat pada tabel diatas mengidentifikasi kemampuan persamaan regresi berganda untuk menunjukan tingkat penjelasan model terhadap variabel dependen. Besarnya $R^{2}$ yaitu 0,266 atau sebesar $26,6 \%$ yang berarti variabel dependen dapat dijelaskan oleh variabel independen dalam penelitian ini sebesar $26,6 \%$ sedangkan sisanya $73,4 \%$ dijelaskan oleh faktor-faktor lain di luar model.

\section{Kesimpulan}

Dari hasil uji penelitian dan pembahasan yang telah dilakukan sebelumnya, maka dapat disimpulkan bahwa variabel usia, tingkat Pendidikan, dan biaya perjalanan tidak berpengaruh signifikan terhadap jumlah kunjungan wisatawan ke Desa Wisata Alam Kalibiru. Sementara itu, variabel pendapatan dan jarak tempuh memiliki hasil yang sesuai dengan yang diharapkan atau dalam kata lain pendapatan dan jarak tempuh memiliki pengaruh yang signifikan terhadap peningkatan jumlah kedatangan wisatawan pada Desa Wisata Alam Kalibiru.

Untuk meningkatkan tingkat kunjungan wisatawan pada Wisata alam Kalibiru dapat dilakukan dengan cara menjaga atau meningkatkan kualitas wisata tersebut seperti perawatan sarana dan prasarana serta meningkatkan pengawasan agar fasilitas tidak 
mudah dirusak oleh pengunjung. Selain itu, perlu ditingkatkannya promosi melalui internet, surat-menyurat, pemberian brosur, atau memasang papan petunjuk arah ke Wisata Alam Kalibiru sebagai sarana publikasi.

Bagi pengelola objek Wisata Alam Kalibiru untuk lebih memperhatikan pelayanan terutama dalam memberikan fasilitas tambahan seperti pelayanan ojek gratis dari tempat parkir menuju objek wisata, spot foto, tempat untuk bersantai, dan fasilitasfasilitas permainan khusus anak-anak untuk menarik minat wisatawan dalam berkunjung dan berwisata ke objek Wisata Alam Kalibiru. Selain itu, bagi pengelola objek wisata alam Kalibiru diharapkan mampu menurunkan tarif atau biaya foto di setiap spot yang ada.

\section{Daftar Pustaka}

Akhrom, K, M. (2014). Analisis Faktor-faktor yang Mempengaruhi Kunjungan Wisatawan di Pantai Cahaya, Weleri, Kabupaten Kendal. Skripsi. Universitas Diponegoro Semarang.

Brata., Yolaminda., \& Amalius, D. (2018). Pengarub Pendidikan, Pendapatan, Pengetabuan Jarak terbadap Kesediaan Membayar Wisatawan pada Objek. Wisata Pulau Mandeb Kabupaten Pesisir Selatan. STKIP PGRI. Sumatera Barat.

Dinas Kebudayaan Pariwisata Pemuda dan Olahraga Kabupaten Kulon Progo. (2018). Kabupaten Kulon Progo dalam Angka Tahun 2018. Dinas Kebudayaan Pariwisata dan Olahraga Kabupaten Kulon Progo, Yogyakarta.

Lakuhati, J, R., Pangemanan, P, A., Pakasi, C, B, D. (2018). Faktor-faktor yang Mempengaruhi Kunjungan Wisatawan Ke Kawasan Ekowisata di Desa Bahoi Kecamatan Likupang Barat Kabupaten Minahasa Utara. Agri-SosioEkonomi Unsrat. 14(1), 215 -222. https:// doi.org/10.35791/agrsosek.14.1.2018.19268

McIntosh, R. W., Goeldner, C. R., \& Ritchie, J. R. B. (1995). Tourism Principles, Practices, Philosophies. New York : John Wiley \& Sons.

UNESCO Office Jakarta and Regional Bureau for Science in Asia and the Pacific. (2009). Ekowisata: panduan dasar pelaksanaan. Jakarta: Unesco Office. 